required the Committee selected for experiment the operations involved in type-setting by hand. Their conclusions are of considerable importance on both the commercial and scientific aspects. In addition to measuring the total output under varying conditions of illumination, a record was also kept of all mistakes, particularly those in connection with turned letters, as this form of error is mainly due to the failure of the operator to see the nicks on the type. The optimum value of illumination was found to be about 20 foot-candles, an illumination considerably in excess of that usually provided. With illumination as powerful as this, it is, of course, necessary to make careful provision for the avoidance of glare. When the illumination fell below 2 foot-candles nearly one-quarter of the output was lost. With an illumination of 10 footcandles there was no complaint of ocular fatigue but the output was increased and the number of errors reduced by raising the light to a higher value. Artificial daylight was also tried. This did not meet with the approval of the compositors, and, although there was a slight increase in the output, there was also a slight increase in the total number of errors. As artificial daylight was only used for two days the committee do not consider the question as settled in view of the time found necessary for adaptation to various sources of illumination. In any case the low efficiency of artificial daylight illumination renders its employment too costly for commercial purposes.

\title{
"Sesquipedalia verba"
}

In 1855, James Dixon, Surgeon to the Royal London Ophthalmic Hospital and formerly of St. Thomas's Hospital, brought out a severely practical handbook on Diseases of the Eye. The following extract from the preface may interest our readers, and cause a feeling of thankfulness in us all that we were not in active practice at the time when such words were in use :

"Technical terms are of course as indispensable in medicine as in any other science ; they avoid circumlocution, and, if well chosen, carry with them their own definition; but to attempt expressing by single words every process of disease, and every surgical manipulation, imparts a dry and pedantic character to subjects which would be attractive and interesting if described in a simple and natural way. It requires a more intimate knowledge of Greek than one has any right to expect from every student of medicine, to recognize in Irido-periphakitis an inflamed iris and capsule; or at once to detect the operation for closing a lacrymal fistula under such a disguise as that of Dacryocystosyringokatakleisis." 